\title{
CONTRIBUTION OF SMALL HABITAT FRAGMENTS TO CONSERVATION OF INSECT COMMUNITIES OF GRASSLAND-CROPLAND LANDSCAPES
}

\author{
Teja Tscharntke, ${ }^{1}$ Ingolf Steffan-Dewenter, Andreas Kruess, and Carsten Thies \\ Agroecology, University of Göttingen, Waldweg 26, D-37073 Göttingen, Germany
}

\begin{abstract}
Habitat destruction and fragmentation of remaining habitat are major threats to global biodiversity. In this paper, we drew upon data from grassland butterflies, legumefeeding herbivores and their parasitoids, and the interactions between rape pollen beetles and their parasitoids in the agricultural landscapes of Germany to explore the following issues: (1) the relative importance of small habitat fragments for the conservation of biodiversity (in contrast to the prevailing arguments in favor of large fragments); (2) the disruption of interspecific interactions in fragmented habitats; and (3) the relative importance of the spatial arrangement of habitat fragments in landscapes of different complexity.

The percentage of polyphagous butterfly species and their abundance were higher in small than in large calcareous grassland fragments, showing the relative importance of the landscape surrounding habitat fragments for less specialized species. A landscape perspective is also needed to explain why several small fragments supported more butterfly species (even when only endangered species were considered) than the same area composed of only one or two fragments. Analyses of insects on legumes showed trophic-level differences, in that species numbers of parasitoids, but not of herbivores, benefited from habitat subdivision in landscapes. As percentage of parasitism (i.e., the strength of ecological interactions) increased with fragment area, both the "several small" and "single large" strategies appeared to have merit. An intermediate-fragmentation strategy of habitat conservation in human-dominated landscapes may combine the advantages. Small habitat fragments should be scattered enough to cover a range of geographical area wide enough to maximize beta diversity and the spreading of risk, but with large habitat fragments close enough to enable dispersal among fragments, to reduce the extinction probability of areasensitive species, and to stabilize predator-prey interactions.

Parasitism of rape pollen beetles exhibited a distinct edge effect: it was higher near the crop field edge, i.e., near the parasitoids' overwintering sites (such as grassy strips). However, this was only true in landscapes dominated by annual crops; in landscapes with a high percentage of permanent noncrop area $(>20 \%)$, such edge effects disappeared, presumably because of the high overall density of these parasitoids. These data indicate that spatial configuration is important to mitigate extinction risks when habitat availability in a landscape is low, whereas no effect will be observed when overall area of habitat is high.

Key words: biodiversity; biological control; butterflies; conservation; ecological functions; habitat fragmentation; interspecific interactions; parasitoids; reserve design; scale dependence; SLOSS; trophic interactions.
\end{abstract}

\section{INTRODUCTION}

Habitat destruction and fragmentation of remaining habitat are major threats to global biodiversity (e.g., Wilcove et al. 1986, Quinn and Harrison 1988, Baur and Erhardt 1995). Habitat fragmentation may refer to natural or anthropogenic habitat patchiness. In the second case, which is typical in the human-dominated landscapes of Central Europe, the process producing a pattern of habitat fragments may be defined as a disruption of habitat continuity resulting in a mosaic of

Manuscript received 15 September 2000; revised 25 Apri 2001; accepted 24 May 2001; final version received 26 June 2001. For reprints of this Invited Feature, see footnote 1, p. 319.

${ }^{1}$ E-mail: ttschar@gwdg.de remnant habitats surrounded by a more or less hostile (mainly agricultural) area in the landscape. As a result of the intensification of agricultural production, including fertilization and pesticide application, most of the extensively managed land-use systems, e.g., the species-rich grasslands, were destroyed, particularly from the 1950s onward (Jedicke 1994). Species are differentially affected by habitat fragmentation, so community structure, interspecific interactions, and ecological functions may also change. Usually, species richness and the strength of interactions covary (e.g., trophic interactions among insect species; Didham et al. 1996, Tscharntke and Kruess 1999), but such relations between biodiversity and ecological functions are still controversial (Naeem 2000, Wardle et al. 2000). 
Given a finite total area that can be set aside for conservation in human-dominated landscapes, what spatial configuration would represent the best strategy (see Whittaker 1998)? The conservation value of small habitats is a matter of debate, although conservationists, in practice, often have little influence on fragment configuration. In Germany in 1993, 4883 reserves protected 601928 ha (1.7\% of the area), and two thirds of the reserves (in western Germany) were $<50$ ha. In addition, there are $\geq 40000$ very small reserves ("natural monuments"; estimation for western Germany) that cover an area of only hundreds to maximally thousands of square meters (and rarely up to 2-5 ha; Jedicke 1994). This reality of a mosaic of small-scale reserves contrasts with the recent emphasis on large-scale conservation (see Schwartz 1999).

In this paper, we examine how habitat fragmentation affects insect community structure and the interactions between phytophagous insects and their natural enemies. Species-area and abundance-area relationships may look different depending on the species' trophic level or resource specialization, so the biotic interactions may also change (e.g., Holt et al. 1999). We further examine the relative importance of small habitat fragments for the conservation of biodiversity. In contrast to the prevailing arguments in favor of large habitats, "several small" habitat fragments rather than a "single large" one may better conserve maximum biodiversity (the so-called "SLOSS" debate: "Single Large or Several Small"; Quinn and Harrison 1988, Burkey 1989, Whittaker 1998). A sample of many reserves covers a wider geographic range, thereby maximizing species richness, but in each of the small fragments, persistence of populations and ecological interactions are reduced. Last but not least, we discuss the importance of the spatial arrangement of habitat fragments for the conservation of species and the enhancement of naturally occurring biological control. The question arises whether the spatial arrangement of habitat fragments may compensate for overall habitat loss and mitigate extinction risks (Kareiva and Wennergren 1995) or not (Fahrig 1997, Harrison and Bruna 1999). The answer may depend on the type of landscape structure, as the relative importance of local habitat quality for the strength of biotic interactions may decrease with increasing complexity of the surrounding landscape (Thies and Tscharntke 1999, Östman et al. $2001 a, b)$.

We test these ideas using data from different insect taxa (butterflies, legume-feeding herbivores, and their parasitoids) and the interactions between rape pollen beetles and their parasitoids. The studies were conducted in the human-dominated landscapes of Germany, which are typically characterized by intensive agricultural land use, affecting more than half of the area, and by sharply contrasted habitat mosaics. In these highly fragmented agricultural landscapes, bio- diversity conservation is an important issue in landscape management.

\section{Methods}

The butterfly study was conducted near Göttingen, Germany, on 33 calcareous grasslands ranging in size from 300 to $76000 \mathrm{~m}^{2}$. Butterflies (including burnets) were sampled along five transects between June and September through each of the 33 grasslands, recording the number of individuals of each species within 2.5 $\mathrm{m}$ on either side of, and $5 \mathrm{~m}$ in front of, the observer (see Steffan-Dewenter and Tscharntke 2000). To take into account the increasing fragment size, transect time was $15 \mathrm{~min}$ on grasslands $<1500 \mathrm{~m}^{2}, 30 \mathrm{~min}$ on grasslands of $1500-5000 \mathrm{~m}^{2}, 45 \mathrm{~min}$ on grasslands of 5000 $10000 \mathrm{~m}^{2}$, and $60 \mathrm{~min}$ on grasslands $>10000 \mathrm{~m}^{2}$. Abundance (number of specimens per square meter) was calculated as the ratio of the number of observed specimens to the transect area (in square meters).

Endophagous insects of natural clover and vetch populations were studied in orchard meadows near Karlsruhe, Germany, ranging in size from 0.03 to 70 ha. We dissected 60 flower heads and 120 stems of red clover (Trifolium pratense) per meadow ( $n=19$ meadows). They contained eight herbivore and 15 parasitoid species, whereas the 200 pods of the bush vetch (Vicia sepium) sampled per meadow ( $n=18$ meadows) contained four herbivore and 10 parasitoid species (data from Kruess and Tscharntke 1994, 2000a, b).

Landscape structure was estimated in 15 circular landscape sectors with a diameter of $1.5 \mathrm{~km}$ around Göttingen, Germany, by using aerial photographs and intensive field inspections. Parasitism of rape pollen beetles was analyzed by dissection of last instar larvae in May near the edge ( $1 \mathrm{~m}$ into the field) and toward the center (10-12 m into the field) of winter rape fields (Brassica napus) situated in the middle of each landscape sector ( $>80$ dissected larvae per landscape). Beetle larvae from 2-4 subsamples, comprising all flowers from $0.25 \mathrm{~m}^{2}$, were sampled in each of the 15 landscapes (data from Thies and Tscharntke 1999).

\section{RESUlts}

In the butterfly study, we recorded 61 species (54 butterflies and seven burnets), including four monophagous species, 20 strongly oligophagous species (restricted to one host plant genus), 27 oligophagous species (restricted to one host plant family), and 10 polyphagous species (known to feed on host plants from more than one host plant family). Overall species richness was positively correlated with fragment area $\left(r^{2}\right.$ $=0.514, n=33, P<0.001)$. The percentage of monophagous butterfly species increased with fragment area, whereas the percentage of polyphagous species decreased (Fig. 1). The response of oligophagous species was intermediate and did not show a significant relationship. Abundance-area relationships also dif- 

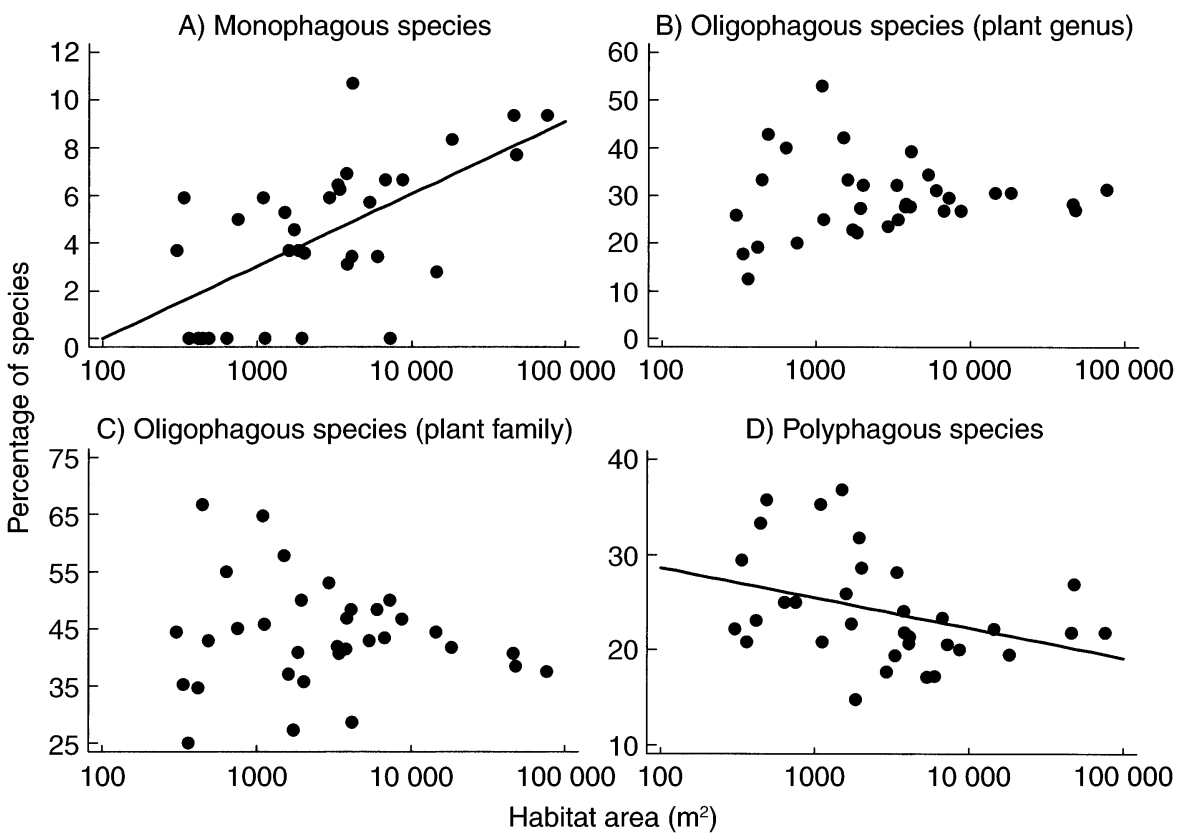

FIG. 1. Percentage of monophagous, strongly oligophagous, oligophagous, and polyphagous butterfly species in relation to the area of calcareous grasslands $\left(\mathrm{m}^{2}\right)$. (A) Percentage of monophagous species vs. $\log$ area $(y=-6.06+3.03 \log x, F$ $\left.=19.05, r^{2}=0.381, n=33, P<0.001\right)$. (B) Percentage of strongly oligophagous species feeding on one plant genus $\left(r^{2}\right.$ $=0.007, P=0.653)$. (C) Percentage of oligophagous species feeding on one plant family $\left(r^{2}=0.01, P=0.573\right)$. (D) Percentage of polyphagous species vs. $\log$ area $\left(y=34.96-3.16 \log x, F=4.54, r^{2}=0.128, n=33, P=0.04\right)$.

fered in relation to the degree of food-plant specialization. Monophagous species showed an increase in abundance with area, whereas the less specialized oligophagous and polyphagous species decreased in abundance (Steffan-Dewenter and Tscharntke 2000). We used these butterfly communities to test the idea of Quinn and Harrison (1988) that the same habitat area may harbor different numbers of species depending on whether it is composed of "single large or several small" fragments (the SLOSS debate). The graphical presentation (Fig. 2A) shows that 10 ha of calcareous grassland may either support $98 \%$ of all butterfly species when this area is composed of many small fragments (30 fragments) or only $50-60 \%$ of all species when this area is composed of only 1-2 large fragments. To give another example of how to read Fig. $2 \mathrm{~A}$, we found $\sim 50 \%$ of all species on 0.1 ha when this area was composed of three small fragments, or on 7.6 ha when this area was composed of only one large fragment. The almost identical pattern, shown in Fig. $2 \mathrm{~B}$, arose when only the endangered butterfly species were considered ( 38 species listed in the red data book of Lower Saxony; Lobenstein 1988). For example, 10 ha of calcareous grassland supported $100 \%$ of the endangered species when this area was composed of 30 fragments, but only $40 \%$ when it was composed of only 1-2 large fragments.

Data from the insect communities reared from red clover and bush vetch provided an opportunity to ad- dress the SLOSS issue by using species from different trophic levels. The response of species richness of herbivores and parasitoids to cumulative area differed greatly (Fig. 3). Although clover and vetch herbivores were rather specialized (nine monophagous and three oligophagous species; Kruess and Tscharntke 2000b), they occurred on almost all fragments. Accordingly, cumulative species numbers only marginally differed between the "small to large" and the "large to small" cumulation of fragments. In contrast, parasitoid communities differed greatly between habitats (nine monophagous, eight oligophagous, three polyphagous, and five species with unknown feeding preferences; Kruess and Tscharntke 2000b). For example, 90 ha of meadows supported $93 \%$ (clover) or $80 \%$ (vetch) of all species when this area was composed of 16 (clover) or 17 (vetch) fragments, but only 58-68\% (clover) or 50$60 \%$ (vetch) when it was composed of only 1-2 fragments (Fig. 3). Increase of species number with area was significantly steeper in parasitoids than in herbivores (Kruess and Tscharntke 2000a, b), and species richness and percentage of parasitism covaried. Percentage of parasitism of both the stem-boring weevils (Catapion virens and Ischnopterapion seniculus) of red clover (Trifolium pratense) and the seed-feeding weevils (Oxystoma ochropus) on bush vetch (Vicia sepium) increased more than threefold from the small to the large fragments (from $\sim 20 \%$ to $70 \%$; Kruess and Tscharntke 2000b). 
A) All butterfly species

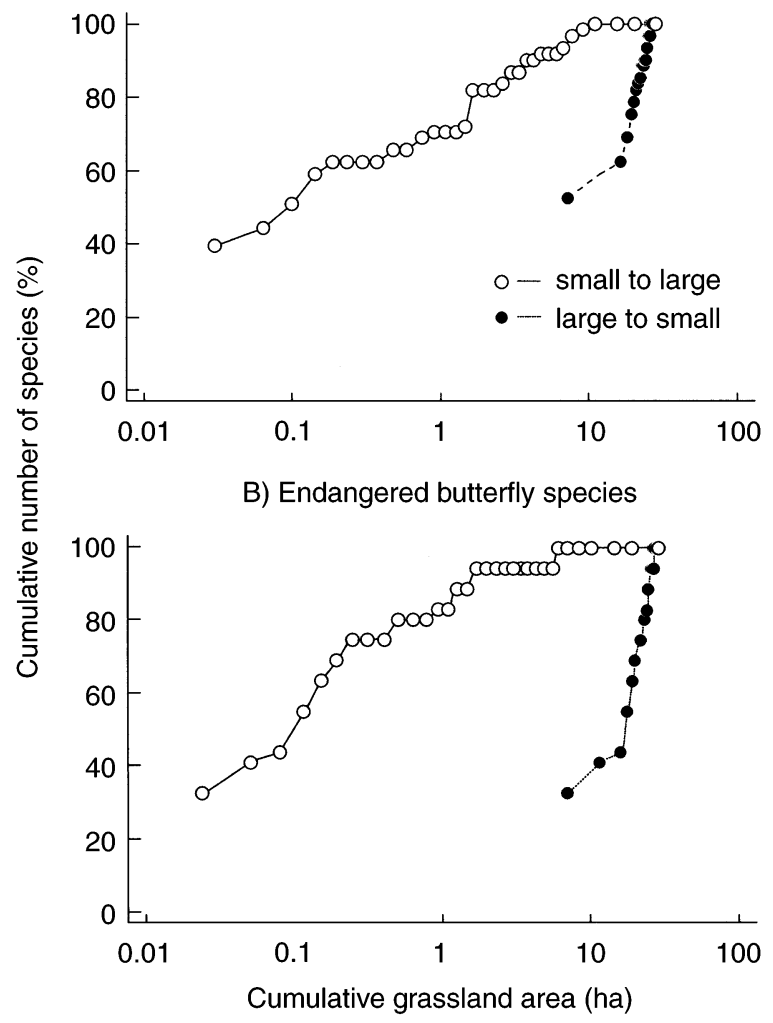

FIG. 2. Cumulative number of butterfly species (percentage of all species) in relation to the cumulative area of calcareous grasslands (ha). Area is cumulated in two ways: (1) starting with the smallest habitats, stepwise adding the next smallest (open points), and (2) starting with the largest habitats, stepwise adding the second largest (filled points). Plots are presented for: (A) all butterfly species and (B) the endangered (red data book) butterfly species.

Habitat fragmentation was studied over a broader landscape scale with respect to the interaction of rape pollen beetles and their parasitoids. Percentage of parasitism increased with percentage of noncrop area in the landscape (Fig. 4). Parasitoids hibernate in the soil and are known to be affected by annual ploughing, which is typical in areas managed for annual crops (Thies and Tscharntke 1999). Results from samples near the edge and near the center of rape fields showed that, in structurally simple landscapes mainly characterized by annual crops and intensive agricultural activity ( $<20 \%$ noncrop area), parasitism at the edge of the crop field was significantly higher than in the center (Fig. 4). Such an edge effect in parasitism occurred only in simple landscapes dominated by annual crop fields; in complex landscapes, the identical parasitism rate recorded both at the edge and the center of the crop field appeared to be due to the high overall parasitoid density.

\section{DISCUSSION}

Our studies show that habitat fragmentation affects species and biotic interactions differentially, with a corresponding change in community structure. Specialized butterflies suffered much more from the fragmentation of their habitat than did the less specialized oligophagous and polyphagous species. Both species richness and abundance of these specialized butterflies were much reduced in small fragments, whereas the less specialized butterflies had only slightly reduced species numbers and even higher densities in small fragments. Such an increase in abundance with fragmentation of habitats points to the significance of the fragments' context and the overall spatial structure of the landscape mosaic. To understand the surprising observation that patchy habitat supported more butterfly species than did the same area composed of only one or two fragments, even when only endangered species were considered, we also need a landscape perspective, which we will address. Species richness of parasitoids of legume-attacking herbivores also increased with habitat subdivision (on a landscape scale), but the strength of ecological interactions (here, percentage of parasitism) increased with area.

Loss of favorable interactions in habitat fragments may affect the local target population through reduced pollination and seed set, seed dispersal, decomposition of dung or litter, or mutualistic mycorrhizal associations (Matthies et al. 1995, Didham et al. 1996). In contrast, disruption of antagonistic interactions may favor target populations and enhance their persistence, in that pathogenic fungal infections, seed predation, or mortality due to predation or parasitism are reduced (Thomas 1989, Hanski et al. 1995, Matthies et al. 1995). The disruption of interactions may lead to additional extinctions, sometimes referred to as "secondary extinctions" (Wilcove et al. 1986). Such cascades of extinctions may simplify food webs and, thereby, overall ecosystem complexity.

Our results on the herbivore-parasitoid interactions on legume host plants provide evidence that habitat fragmentation affects natural enemies more than their phytophagous victims, and releases herbivores from possible control by their natural enemies, adding evidence to the trophic-level hypothesis of island biogeography (Kruess and Tscharntke 1994, Holt et al. 1999, Tscharntke and Kruess 1999). Kareiva (1987, 1990) showed that decreasing area and age in goldenrod fields leads to more frequent local explosions of aphid populations, presumably due to reduced predation.

\section{Should we only conserve large habitat fragments?}

Since the 1990s, conservation practitioners have followed a "bigger is better" philosophy, driven by both the difficulty of managing many small reserves and an urge to incorporate conservation concepts on a regional scale ("bioregions," "sustainable development areas," 


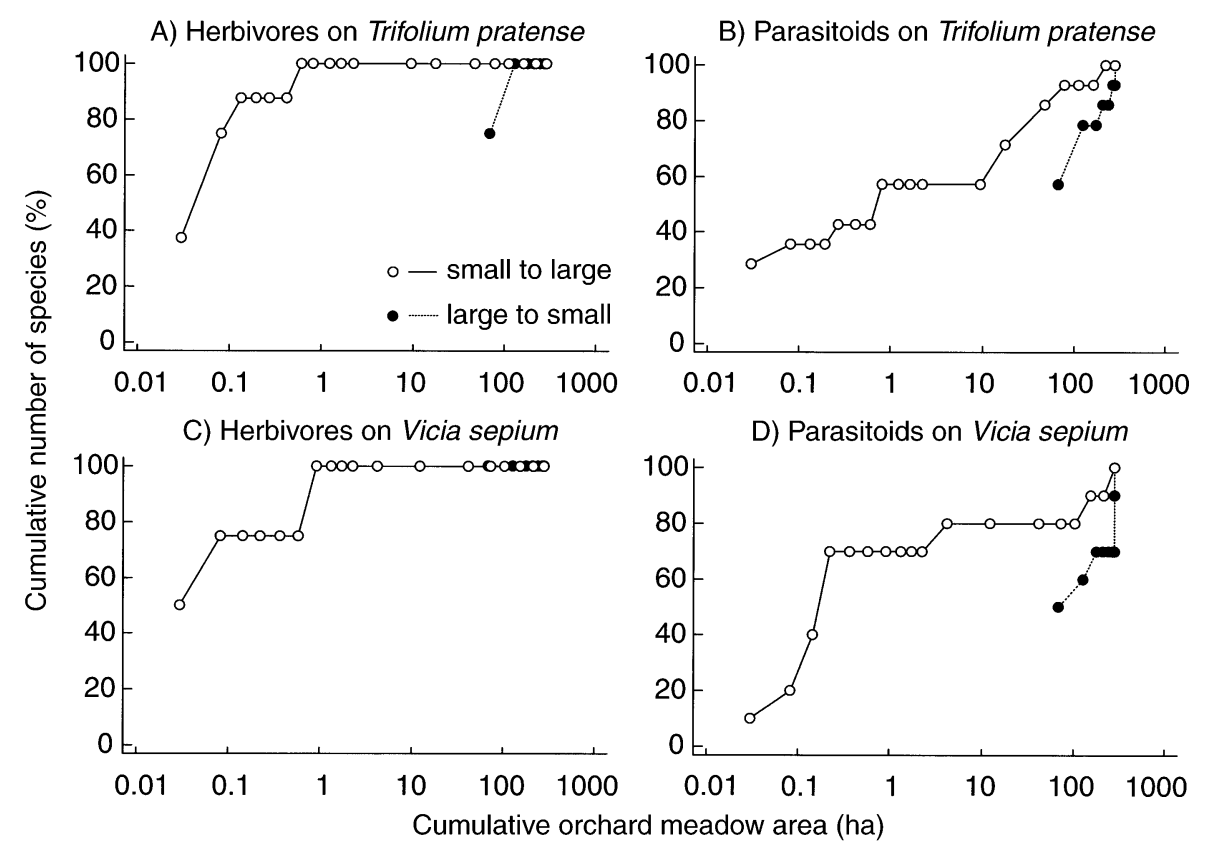

FIG. 3. Cumulative species number of phytophagous insects and their parasitoids (percentage of all species) on Trifolium pratense (A, B) and Vicia sepium (C, D) in relation to the cumulative area of orchard meadows (ha). Area is cumulated in two ways: (1) starting with the smallest habitats, stepwise adding the smallest but one (open points); and (2) starting with the largest habitats, stepwise adding the second largest (filled points). For both host plant species, cumulative numbers of herbivores (A, C) and parasitoids (B, D) are given.

etc.; Schwartz and van Mantgem 1997). In fact, all other things being equal, priority should go to the largest remnants. However, in a landscape perspective, small fragments are often not simply random subsamples from larger ones. Abiotic features of the habitat fragments (e.g., those due to geological or hydrological differences) and the surroundings of the fragments (determining emigration and immigration rates) differ on a geographical scale. Usually, a series of small- or medium-sized reserves capture a much greater habitat and habitat-environment heterogeneity than one large fragment. Species assemblages found in small patches are not simply a random subset of the species pool found in large patches, because both patch quality and community structure change with the site (or geography) of the patch. Habitat heterogeneity makes discontinuous habitat patches more diverse. This is the main reason why, in a landscape-oriented approach to increase biodiversity (particularly when one considers organisms such as plants and insects that require small areas and are sensitive to microhabitat) results favor "many small," not "single large," fragments (Figs. 2 and 3; see the review of Quinn and Harrison [1988] and Shafer [1990]). In a recent small-scale grassland fragmentation experiment, Zschokke et al. (2000) found that between-site differences in gastropod communities were much more pronounced than the fragmentation effect. One may argue that the landscape pattern of butterfly species richness shown in Fig. 2 was caused by com-

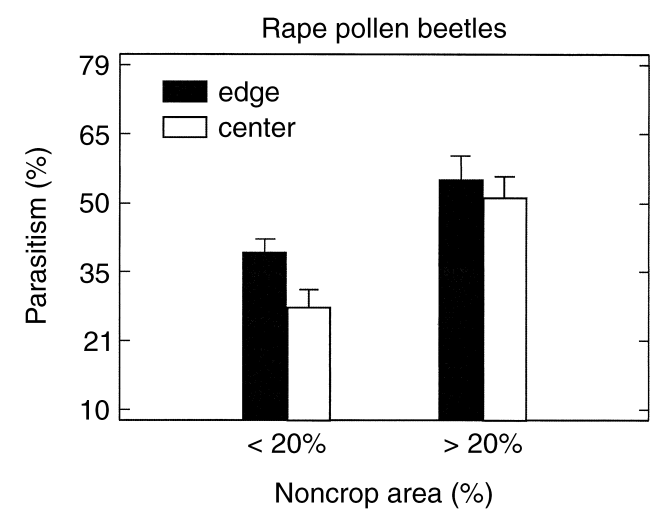

FIG. 4. Parasitism of the rape pollen beetle (Meligethes aeneus) in relation to the percentage of noncrop area in the agricultural landscape. Percentage of parasitism by Tersilochus heterocerus, Phradis interstitialis, and $P$. morionellus in winter rape fields (Brassica napus), and mean percentage $(+1$ SE) of noncrop area per landscape $(n=15$ landscapes with altogether 26 rape crop fields) are given. Computation was done with arcsine square-root transformed percentages of parasitism. Parasitism significantly decreased from the edge to the center in landscapes with $<20 \%$ of noncrop area $(F=$ $6.0, P=0.028, N=16)$, whereas parasitism did not decrease from the edge to the center in landscapes with $>20 \%$ of noncrop area $(F=0.38, P=0.55, N=14)$. 
TABLE 1. Relative advantages of "single large" and "several small" habitat fragments.

\begin{tabular}{|c|c|c|c|}
\hline Variable & "Single large" & "Several small" & References \\
\hline Species richness & low & high & $\begin{array}{l}\text { Quinn and Harrison (1988), Bur- } \\
\text { key (1989) }\end{array}$ \\
\hline Abiotic and biotic heterogeneity of patches & low & high & $\begin{array}{l}\text { Quinn and Harrison (1988), Bur- } \\
\text { key (1989) }\end{array}$ \\
\hline $\begin{array}{l}\text { Immigration of many species due to different } \\
\text { landscapes }\end{array}$ & low & high & $\begin{array}{l}\text { Wright and Reeves (1992), Nor- } \\
\text { ton et al. (2000) }\end{array}$ \\
\hline Focus on local relicts of diversity hot spots & low & high & $\begin{array}{l}\text { Johnson (1996), Schwartz and } \\
\text { van Mantgem (1997), } \\
\text { Schwartz (1999) }\end{array}$ \\
\hline $\begin{array}{l}\text { Risks due to environmental catastrophes and } \\
\text { epidemics }\end{array}$ & high & low & $\begin{array}{l}\text { den Boer (1990), Hess (1996), } \\
\text { Fagan et al. (2001) }\end{array}$ \\
\hline Importance of biotic interactions & high & low & $\begin{array}{l}\text { Didham et al. (1996), Holt et al. } \\
\text { (1999), Tscharntke and Kruess } \\
\text { (1999) }\end{array}$ \\
\hline Probability of extinction & low & high & $\begin{array}{l}\text { Shaffer (1981), Wilcove et al. } \\
\text { (1986), Burkey (1989) }\end{array}$ \\
\hline Dependence on conspecific immigrants & low & high & Brown and Kodric-Brown (1977) \\
\hline Conservation of fragmentation-sensitive species & high & low & $\begin{array}{l}\text { Wilcove et al. (1986), Soulé and } \\
\text { Simberloff (1986), Shafer } \\
\text { (1990), Whittaker (1998) }\end{array}$ \\
\hline Negative edge effects & low & high & $\begin{array}{l}\text { Laurance and Yensen (1991), } \\
\text { Harrison and Bruna (1999) }\end{array}$ \\
\hline Persistence of habitat quality & high & low & $\begin{array}{l}\text { Wilcove et al. (1986), Shafer } \\
\text { (1990) }\end{array}$ \\
\hline
\end{tabular}

mon species with little conservation value and with preferences for habitat edges. However, the analysis including only the endangered (and specialized) species showed that a sample of several small and geographically more widespread fragments supported many more Red Data Book endangered species than did only one or few large fragments.

Our analyses of the insect assemblages of clover and vetch insects from small and large meadows allowed us to test for trophic-level differences with respect to the SLOSS debate. In fact, "several small" meadows supported more parasitoid, but not herbivore, species than did "single large" meadows (Fig. 3). The herbivore, but not the parasitoid, species were present in almost all fragments, so parasitoid populations appeared to be more affected by the spatial configuration of habitat fragments than were their hosts. Specialized high-trophic-level species such as parasitoids should suffer from (1) increased extinction rates (due to the reduced population size with trophic rank and the increased population variability as a result of dependence on the local population variability of low-ranked species); and (2) reduced colonization rates (because their dependence on the successful colonization of lowranked species and their limited dispersal ability do not compensate for the host-dependent local population fluctuations and following extinctions; see Holt et al. 1999, Tscharntke and Kruess 1999, Walde and Nachman 1999, Holyak 2000). This pattern is in support of Holt (1996): food web ecology needs spatial perspectives, as interacting communities are made up of species with greatly differing spatial strategies. On the one hand, single large fragments were characterized by a greater parasitoid species richness and parasitism rate; on the other hand, several small habitats of the same area, but spatially separated, provided more parasitoid species and thereby a greater potential of biologicalcontrol agents for future landscape development. In conclusion, both strategies have merit because both species richness and enhanced density are important in biological control.

The concentration of conservation efforts on large habitat fragments and the devaluation of small fragments does not appear to be justified, based on the arguments listed in Table 1. Species richness is maximized by sampling many small habitat fragments, primarily because they cover a wide geographic scale (Burkey 1989). Habitat differences will almost always increase with the number of habitat fragments, and these differences will be reflected by the flora and fauna. Further, ecosystems adjacent to each of the many reserves differ; altogether, they represent a broader spectrum of habitats and populations than do single large reserves, with corresponding effects on potential immigration. When early colonists are able to preempt the habitat and inhibit later invasion (Connell and Slatyer 1977, Quinn and Harrison 1988), differences between fragments may be enhanced by such historical priority effects. Importance of biotic interactions is reduced in small fragments, which may enhance some populations and handicap others.

In Central Europe, small reserves are often relicts in an intensively managed landscape and provide rare soil and microclimatic conditions or a rare blend of attri- 
butes. Such small reserves are often much less than 1 ha (for details, see the Introduction), but are the only representatives of certain ecosystem types. For example, fragments of chalk grasslands with southern slopes and extremely dry and nutrient-poor soils may support the only populations of endangered plants and insects in landscapes that are typically characterized by cultivation, fertilization, and residential development. In such cases, conservation has to rely on these regional diversity hot spots because alternatives are lacking. High-diversity reserves with narrowly restricted populations may also be naturally small, such as the small, isolated granitic outcrops of the southern Appalachians, with their high numbers of endemic species (Johnson 1996, Schwartz 1999). If diversity is scattered only over small patches, these patches have to be the focus of conservation.

In contrast, population persistence in small habitat fragments may depend on conspecific immigrants from the large source populations of large habitats (Brown and Kodric-Brown 1977), and extinction risk on small or isolated islands is always higher, especially in fragmentation-sensitive species with large home ranges, such as vertebrates compared to invertebrates. Large vertebrate flagship species are often the target of conservation and, in this case, there is no debate on the superiority of large over small reserves (Soulé and Simberloff 1986). Effects of habitat configuration will vary greatly depending on the type of organisms involved (Lawton 1995, Whittaker 1998). Home ranges of organisms span orders of magnitude, so management should consider different spatial scales. Negative edge effects are minimized in large fragments (Laurance and Yensen 1991), emphasizing the significance of reserve shape (Diamond and May 1981). Persistence of habitat quality with time is more probable in large than in small fragments. Each of the small patches is more prone to rapid degradation and destruction than are large areas, but environmental catastrophes (fire, introduced predators) and unforeseen epidemics exhibit the advantages of a risk-spreading strategy with several fragments. Many spatially separated populations may also provide numerous sources of conspecific colonists mitigating extinction risk through local variability of populations, which is known to affect the local persistence of most populations (Fagan et al. 2001). In strongly interacting food webs, intermediate degrees of habitat subdivision may provide spatial refuges and promote persistence of species that would be driven to extinction within undivided habitats (Holyak 2000). At both low and high levels of subdivision, one species could drive another to extinction, and rates of patch extinction exceed rates of patch colonization (Kareiva 1990, Holyak 2000). Fragment-specific disturbance regimes may also enhance between-fragment heterogeneity and corresponding biodiversity.

The pros and cons of habitat fragmentation favor a trade-off between conserving viable populations in "single large" habitat fragments vs. the greater biodiversity in "several small" habitat fragments. A focus on minimizing extinction favors the "single large" strategy, whereas a focus on maximizing species richness favors the "several small" strategy. In most cases, small fragments will be better designed and more carefully placed in the landscape to fulfill well-devised conservation issues, to maintain populations of certain target species, to enhance wanted interactions, or to preserve local diversity hot spots.

A given amount of a habitat, such as chalk grassland in an agricultural landscape, may be continuous or chopped into many small parts. An intermediate-fragmentation strategy may combine the advantages: habitat fragments of small or intermediate size should be scattered enough to cover such a wide range of geographical area that beta diversity and spreading of risk are maximized, but that large habitat fragments are close enough to enable dispersal among fragments, to reduce the extinction probability of fragmentation-sensitive species, and to stabilize predator-prey interactions.

\section{Landscape structure and spatial arrangement of habitat patches}

On oceanic islands, the marine environment is a clear isolation barrier, but in terrestrial habitat islands, the contribution of the surrounding landscape to the reproduction and life-span of organisms is mostly unknown (e.g., Gustafson and Gardner 1996). The structure of the surrounding landscape is particularly important when species mainly prefer one habitat type, but are also able to utilize different parts of the landscape (termed "habitat compensation"; Norton et al. 2000). In our study of butterflies on calcareous grassland, population densities of monophagous species increased, whereas oligophagous and polyphagous species decreased with habitat area. The pattern of the butterfly specialists is in agreement with metapopulation theory (Hanski 1994) and experimental data (Gonzales et al. 1998). The high density of oligophagous and polyphagous butterfly species in small fragments may reflect the accumulation of individuals from the surrounding landscape, as these fragments provide the only flower-rich resources. Such a temporary crowding effect may differ from possible refuge or retreat effects in other systems that also cause negative density-area relationships. The area around the fragments may offer only suboptimal resources, but may still function as additional foraging area or larval habitat and, thereby, permanently enhance the fragments' populations and give rise to inverse relations between fragment area and population density (Debinsky and Holt 2000, Norton et al. 2000, Zschokke et al. 2000).

Communities are composed of species that experience the landscape on a broad range of spatial scales 
(Holt 1996, Debinsky and Holt 2000). For example, anthropogenic forest fragmentation affects parasitism and may promote tent caterpillar (Malacosoma disstria) outbreaks (Roland and Taylor 1995, 1997). The spatial scale at which forest structure had its greatest effect on abundance differed among parasitoid species: parasitism of the largest species was correlated with forest structure at a rather large scale; the smaller the species, the smaller the spatial scale which correlated with parasitism (Roland and Taylor 1995, 1997). Similarly, the abundance of the social honey bees was best explained by a much larger sector of the landscape than the abundance of solitary bees, which are known to have a smaller home range (Steffan-Dewenter et al. 2001). In general, abundance and distribution of species with large home ranges or high trophic levels should depend on a larger scale of fragmented landscapes than for species with small home ranges or low trophic levels (Holt 1996), and such differences may affect community structure and interactions.

Parasitism of rape pollen beetles showed a distinct edge effect: parasitism was greater near the crop field edge and thereby, near the parasitoids' overwintering habitats such as grassy strips. However, this was only true in landscapes dominated by annual crops $(<20 \%$ noncrop area). In landscapes with a high percentage of permanent noncrop area, such edge effects disappeared, presumably due to the high overall density of these parasitoids (Fig. 4). The value of $20 \%$ noncrop area is based on the observation that, below this threshold value, the percentage of parasitism was found to drop below 32-36\%, below which a success in classical biological control has never been found (Hawkins and Cornell 1994). Accordingly, this ecological process (parasitism of a pest insect) was affected both by local habitat configuration and by landscape structure. This result is related to a recent debate about the potential role of the spatial arrangement of habitat fragments in the mitigation of extinction risks. This may be expected (Kareiva and Wennergren 1995), or not, to compensate for overall habitat loss (Fahrig 1997, Harrison and Bruna 1999). Our results suggest that the spatial arrangement of habitat is important for the conservation of diversity and ecological functions when habitat availability in a landscape is low, and appears to be of minor value when habitat availability is high. These empirical findings support mathematical models that predict increasing effects of fragment area and isolation with decreasing proportions of suitable habitat (Andrén 1996). Hence, restriction of fragmentation studies to species-area relationships without a consideration of the landscape mosaic seems to be inappropriate at the lower end of a gradient in habitat availability.

The potential for biological control is directly related to the spatial arrangement of habitat structures (e.g., Ekbom et al. 2000, Tscharntke 2000). Natural enemies often depend on resources found only in noncrop hab- itats, such as alternative prey, pollen and nectar resources (for adult parasitoids and syrphid flies), and nearby overwintering habitats, e.g., for the parasitoids of Californian grape leafhoppers or the parasitoids of European rape pollen beetles (Corbett and Rosenheim 1996, Thies and Tscharntke 1999). Diversification of crops and the establishment of perennial vegetation adjacent to annual crop fields are management practices that attract natural enemies to crop pests and stabilize enemy-pest interactions. A close neighborhood of perennial fallows and annual crops such as winter rape may reduce damage by insect pests and increase the pests' mortality due to parasitoids (Thies and Tscharntke 1999). In the conservation of biological control, species richness and the strength of desired ecological interactions such as predation and parasitism of pests may covary or not. Both species richness of parasitoids and mortality of legume herbivores increased with the area of habitat fragments (Fig. 4; see also Tscharntke 1992, Riechert et al. 1999, Kruess and Tscharntke 2000a), but species richness of predators and predator-prey ratios did not covary in a comparison of differently managed field margin strips (Denys and Tscharntke 2001).

In conclusion, small habitat fragments deserve more attention than recent publications suggest, as shown by the comparisons of "single large" vs. "several small" habitat fragments. This is not to maximize the richness of opportunistic edge species, but to conserve populations of endangered butterflies and high trophic-level specialists such as parasitoids. Soulé and Simberloff's (1986) argument that "nature reserves should be as large as possible, and there should be many of them" is irrefutable, but in the agriculturally dominated landscapes of Central Europe, where only a small fraction of the area is reserved for conservation, focusing strictly on large reserves may not be a realistic way to maximize species richness. An intermediate level of habitat fragmentation may provide more habitat types and environments than one very large reserve would be able to capture. In addition, the spatial arrangement of habitat fragments in a landscape appears to be of greater importance than is often suggested, particularly when habitat availability in a landscape is low. Species richness and strength of ecological functions are often desirable in a certain locality, for example in the conservation strategy to enhance biological control (just described). Attention to spatial arrangement is also necessary in the conservation of the small European reserves because of the focus on locally well-known biodiversity hot spots.

\section{ACKNOWLEDGMENTS}

The comments of Marc-André Villard and three anonymous referees improved the paper greatly. This study was financially supported by the Deutsche Forschungsgemeinschaft (DFG, the German Science Foundation). 


\section{LiterATURE Cited}

Andrén, H. 1996. Population responses to habitat fragmentation: statistical power and the random sample hypothesis. Oikos 76:235-242.

Baur, B., and A. Erhardt. 1995. Habitat fragmentation and habitat alterations: principal threats to most animal and plant species. Gaia 4:221-226.

Brown, J. H., and A. Kodric-Brown. 1977. Turnover rates in insular biogeography: effects of immigration on extinction. Ecology 58:445-449.

Burkey, T. V. 1989. Extinction in nature reserves: the effect of fragmentation and the importance of migration between reserve fragments. Oikos 55:75-81.

Connell, J. H., and R. O. Slatyer. 1977. Mechanisms of succession in natural communities and their role in community stability and organization. American Naturalist 111:11191144.

Corbett, A., and J. A. Rosenheim. 1996. Impact of a natural enemy overwintering refuge and its interaction with the surrounding landscape. Ecological Entomology 21:155164.

Debinsky, D. M., and R. D. Holt. 2000. A survey and overview of habitat fragmentation experiments. Conservation Biology 14:342-355.

den Boer, P. J. 1990. The survival value of dispersal in terrestrial arthropods. Biological Conservation 54:175-192.

Denys, C., and T. Tscharntke. 2001. Plant-insect communities and predator-prey ratios in field margin strips, adjacent crop fields, and fallows. Oecologia, in press.

Diamond, J. M., and R. M. May. 1981. Island biography and the design of natural reserves. Pages 228-252 in R. M. May, editor. Theoretical ecology. Blackwell Scientific, Oxford, UK.

Didham, R. K., J. Ghazoul, N. E. Stork, and A. J. Davis. 1996. Insects in fragmented forests: a functional approach. Trends in Ecology and Evolution 11:255-260.

Ekbom, B., M. Irwin, and Y. Robert, editors. 2000. Interchanges of insects between agricultural and surrounding landscapes. Kluwer Academic, Dordrecht, The Netherlands.

Fagan, W. F., E. Meir, J. Prendergast, A. Folarin, and P. Kareiva. 2001. Characterizing population vulnerability for 758 species. Ecology Letters 4:132-138.

Fahrig, L. 1997. Relative effects of habitat loss and fragmentation on population extinction. Journal of Wildlife Management 61:603-610.

Gonzales, A., J. H. Lawton, F. S. Gilbert, T. M. Blackburn, and I. Evans-Freke. 1998. Metapopulation dynamics, abundance, and distribution in a microecosystem. Science $\mathbf{2 8 1}$ : 2045-2047

Gustafson, E. J., and R. H. Gardner. 1996. The effect of landscape heterogeneity on the probability of patch colonization. Ecology 77:94-107.

Hanski, I. 1994. Patch-occupancy dynamics in fragmented landscapes. Trends in Ecology and Evolution 9:131-135.

Hanski, I., T. Pakkala, M. Kuussaari, and G. Lei. 1995. Metapopulation persistence of an endangered butterfly in a fragmented landscape. Oikos 72:21-28.

Harrison, S., and E. Bruna. 1999. Habitat fragmentation and large-scale conservation: what do we know for sure? Ecography 22:225-232.

Hawkins, B. A., and H. V. Cornell. 1994. Maximum parasitism rates and successful biological control. Science 266: 1886.

Hess, G. 1996. Disease in metapopulation models: implications for conservation. Ecology 77:1617-1632.

Holt, R. D. 1996. Food webs in space: an island biogeographic perspective. Pages 313-323 in G. A. Polis and K.
O. Winemiller, editors. Food webs. Chapman and Hall, New York, New York, USA.

Holt, R. D., J. H. Lawton, G. A. Polis, and N. D. Martinez. 1999. Trophic rank and the species-area relationship. Ecology 80:1495-1504.

Holyak, M. 2000. Habitat subdividion causes changes in food web structure. Ecology Letters 3:509-515.

Jedicke, E. 1994. Biotopverbund. Verlag Eugen Ulmer, Stuttgart, Germany.

Johnson, B. R. 1996. Southern Appalachian rare plant reintroductions on granitic outcrops. Pages 433-443 in D. A. Falk, C. I. Millar, and M. Olwell, editors. Restoring diversity: strategies for reintroduction of endangered plants. Island Press, Washington, D.C., USA.

Kareiva, P. 1987. Habitat fragmentation and the stability of predator-prey interactions. Nature 326:388-390.

Kareiva, P. 1990. Population dynamics in spatially complex environments: theory and data. Philosophical Transactions of the Royal Society of London, Series B 330:175-190.

Kareiva, P., and U. Wennergren. 1995. Connecting landscape patterns to ecosystem and population processes. Nature 373:299-302.

Kruess, A., and T. Tscharntke. 1994. Habitat fragmentation, species loss, and biological control. Science 264:15811584.

Kruess, A., and T. Tscharntke. 2000a. Species richness and parasitism in a fragmented landscape: experiments and field studies with insects on Vicia sepium. Oecologia 122:129137.

Kruess, A., and T. Tscharntke. $2000 \mathrm{~b}$. Effects of habitat fragmentation on plant-insect communities. Pages 53-70 in B. Ekbom, M. Irwin, and Y. Robert, editors. Interchanges of insects between agricultural and surrounding landscapes. Kluwer Academic, Dordrecht, The Netherlands.

Laurance, W. F., and E. Yensen. 1991. Predicting the impacts of edge effects in fragmented habitats. Biological Conservation 55:77-92.

Lawton, J. H. 1995. Population dynamic principles. Pages 147-163 in J. H. Lawton and R. M. May, editors. Extinction risks. Oxford University Press, Oxford, UK.

Lobenstein, U. 1988. Rote Liste der in Niedersachsen gefährdeten Großschmetterlinge. Informationsdienst Naturschutz Niedersachsen 8:109-136.

Matthies, D., B. Schmid, and P. Schmid-Hempel. 1995. The importance of population processes for the maintenance of biological diversity. Gaia 4:199-209.

Naeem, S. 2000. Reply to Wardle et al. Bulletin of the Ecological Society of America 81:241-246.

Norton, M. R., S. J. Hannon, and F. K. A. Schmiegelow. 2000. Fragments are not islands: patch vs landscape perspectives on songbird presence and abundance in a harvested boreal forest. Ecography 23:209-223.

Östman, Ö., B. Ekbom, and J. Bengtsson. 2001a. Landscape complexity and farming practice influence the condition of polyphagous carabid beetles. Ecological Applications 11: 480-488.

Östman, Ö., B. Ekbom, and J. Bengtsson. 2001b. Farming practice and landscape heterogeneity influence biological control. Basic and Applied Ecology 2:365-371.

Quinn, J. F., and S. P. Harrison. 1988. Effects of habitat fragmentation and isolation on species richness: evidence from biogeographic patterns. Oecologia 75:132-140.

Riechert, S. E., L. Provencher, and K. Lawrence. 1999. The potential of spiders to exhibit stable equilibrium point control of prey: tests of two criteria. Ecological Applications 9:365-377.

Roland, J., and P. D. Taylor. 1995. Herbivore-natural enemy interactions in fragmented and continuous forests. Pages 195-208 in N. Cappucino and P. W. Price, editors. Popu- 
lation dynamics: new approaches and synthesis. Academic Press, San Diego, California, USA.

Roland, J., and P. D. Taylor. 1997. Insect parasitoid species respond to forest structure at different spatial scales. Nature 386:710-713.

Schwartz, M. W. 1999. Choosing the appropriate scale of reserves for conservation. Annual Review of Ecology and Systematics 30:83-108.

Schwartz, M. W., and P. J. van Mantgem. 1997. The value of small preserves in chronically fragmented landscapes. Pages 379-394 in M. W. Schwartz, editor. Conservation in highly fragmented landscapes. Chapman and Hall, New York, New York, USA.

Shafer, C. L. 1990. Island theory and conservation practice. Smithsonian Institution Press, Washington, D.C., USA.

Shaffer, M. L. 1981. Minimum population sizes for species conservation. BioScience 31:131-134.

Soulé, M. E., and D. Simberloff. 1986. What do genetics and ecology tell us about the design of nature reserves? Biological Conservation 35:19-40.

Steffan-Dewenter, I., U. Münzenberg, and T. Tscharntke. 2001. Pollination, seed set, and seed predation on a landscape scale. Proceedings of the Royal Society London, Series B 268:1-6.

Steffan-Dewenter, I., and T. Tscharntke. 2000. Butterfly community structure in fragmented habitats. Ecology Letters 3:449-456.

Thies, C., and T. Tscharntke. 1999. Landscape structure and biological control in agroecosystems. Science 285:893895.

Thomas, C. D. 1989. Predator-herbivore interactions and the escape of isolated plants from phytophagous insects. Oikos 55:291-298.

Tscharntke, T. 1992. Coexistence, tritrophic interactions and density dependence in a species-rich parasitoid community Journal of Animal Ecology 61:59-67.

Tscharntke, T. 2000. Parasitoid populations in the agricultural landscape. Pages 235-253 in M. E. Hochberg and A. R. Ives, editors. Parasitoid population biology. Princeton University Press, Princeton, New Jersey, USA.

Tscharntke, T., and A. Kruess. 1999. Habitat fragmentation and biological control. Pages 190-205 in B. A. Hawkins and H. V. Cornell, editors. Theoretical approaches to biological control. Cambridge University Press, Cambridge, UK.

Walde, S. J., and G. Nachman. 1999. Dynamics of spatially structured mite populations. Pages 163-189 in B. A. Haw kins and $\mathrm{H}$. V. Cornell, editors. Theoretical approaches to biological control. Cambridge University Press, Cambridge, UK.

Wardle, D. A., M. A. Huston, J. P. Grime, F. Berendse, F. Garnier, W. K. Lauenroth, H. Setälä, and S. D. Wilson. 2000. Biodiversity and ecosystem function: an issue in ecology. Bulletin of the Ecological Society of America 81: 235-239.

Whittaker, R. J. 1998. Island biogeography. Ecology, evolution, and conservation. Oxford University Press, Oxford, UK.

Wilcove, D. S., C. H. McLellan, and A. P. Dobson. 1986 Habitat fragmentation in the temperate zone. Pages 237 256 in M. S. Soulé, editor. Conservation biology. Sinauer Associates, Sunderland, Massachusetts, USA.

Wright, D. H., and J. H. Reeves. 1992. On the meaning and measurement of nestedness of species assemblages. Oecologia 92:416-428.

Zschokke, S., C. Dolt, H. P. Rusterholz, P. Oggier, B. Braschler, G. H. Thommen, E. Lüdin, A. Erhardt, and B. Baur. 2000. Short-term responses of plants and invertebrates to experimental small-scale grassland fragmentation. Oecologia 125:559-572. 